\title{
Livability and Social Capital in West Bay, The New Business Precinct of Doha
}

\section{Raffaello Furlan*}

College of Engineering, Department of Architecture and Urban Planning, Qatar University, Doha, Qatar

\begin{abstract}
Scholars argue that there is a mutual relationship between built environment, social interactions (and/or social capital) and livability: the form of the built environment contributes to the construction of social capital and/or enhancement of livability. Therefore in order to enhance livability, the built environment should provide the arena encouraging social activities. The study of the relationship between built environment, social capital and livability has focused on existing spatial environments at macro level or urban scale. Namely, regardless of the interest to this relationship, direct assessment of the extent to which the built environment of West Bay, the new business precinct of Doha, contributes to the formation and enhancement of social capital, has not been investigated yet. Therefore, this research project aims at filling this gap in the literature. The paper argues that the current spatial form of the built environment of West Bay does not facilitate the development of social activities, which in turn contribute the formation of social capital and enhancement of livability.
\end{abstract}

The aim of the paper is to explore and explain the extent to which the spatial form of the built environment of West Bay can be implemented in order to enhance social interactions and/or social capital and, therefore, to contribute to create a more livable environment. Data is obtained from a household survey and focus group interviews that measured the social capital of tenants living in eight high-rise buildings in West Bay, through their involvement in social activities within the built environment. This allowed understanding how the built environment of West Bay should be modified in order to enhance social capital and consequently implement livability in the neighborhood.

The analysis indicates that (1) tenant living in West Bay have low level of social capital and that (2) in order to enhance livability, the spatial form of the neighborhood's built environment needs to be implemented with public spaces, mixed-use neighborhood design, efficient public transport systems, pedestrian and bicycle networks. This would contribute to create a sense of community and expand opportunity for social interactions, which in the end would contribute to enhance livability.

Keywords: Livability; Social capital; Islamic culture; Social needs

\section{Introduction}

Since the mid-seventies, the State of Qatar has been transformed from fishing and pearling based economy into a modern urban society, due to remarkable increase in national income caused by the development of the oil industry. Consequently, Doha, capital of the State of Qatar and also one of the oldest cities in the GCC, has grown economically as well as demographically. In addition, international events such as the 1995's World Youth Cup, the 2005's West Asian Games and the Asian Games in 2006 have contributed to the significant increase in Qatar's population. From 2004 to 2010 there has been an increment from 8 hundred to 1.7 million inhabitants. Namely, the anticipated 2022's World Cup, which has already accelerated the development of large-scale urban, architecture and infrastructure projects, causing major changes to the built environment of Doha, have significantly contributed to attract more expats as work force. It is recognized that nowadays the economy of Qatar is one of the most active economies in the Middle East region, with a rapid growth, in particular for the construction sector [1].

The city has grown from a single core and expanded towards new urban districts' developments (Figures 1-4). The transportation systems were majorly redeveloped and expanded to accommodate the urban fabric expansion of the city. Accordingly to scholars, Qatar government has planned to invest 100 billion USD in the next five years for the development of new infrastructure projects and for the implementation of the conditions of the existing transportation systems [2]. These investments are envisioned with the aim to integrate heritage, economic, sustainability, environment, socio-cultural implementation of Qatar.
At the same time, due to a phenomenon of globalization and a desire for rapid development, the country has witnessed the construction of neighborhoods displaying stunning architectural design buildings influenced by western contemporary architecture [3]. Contemporary Western architecture has grown significantly compared to the traditional trends. While some scholars argue that this process is acceptable, and also inevitable, cause of the globalization phenomenon, others argue that oil wealth and globalization have threatened Islamic culture and traditions by importing Western architectural standards, technology and urban planning strategies. Nowadays the Islamic concepts of unity, harmony and continuity have been forgotten in the rush for 'western way' development: the majority of the new buildings in Middle Eastern cities are designed for another culture and they ended up in creating an alien environment in Islamic communities [46]. Scholars have listed three categories of contemporary architecture in the GCC countries. In the first category, buildings completely ignored the past traditions and are the reflection of produced westernoriented architecture, which ignored the Islamic spirit and undermined traditional culture. In the second one, buildings partially retreated the

*Corresponding author: Furlan R, Assistant Professor, College of Engineering, Department of Architecture and Urban Planning, Qatar University, Doha, Qatar, Tel: +39 04125716; E-mail: raffur@gmail.com

Received August 01, 2015; Accepted August 22, 2015; Published August 27 , 2015

Citation: Furlan R (2015) Livability and Social Capital in West Bay, The New Business Precinct of Doha. Arts Social Sci J 6: 116. doi:10.4172/2151 6200.1000116

Copyright: (c) 2015 Furlan R. This is an open-access article distributed under the terms of the Creative Commons Attribution License, which permits unrestricted use, distribution, and reproduction in any medium, provided the original author and source are credited. 


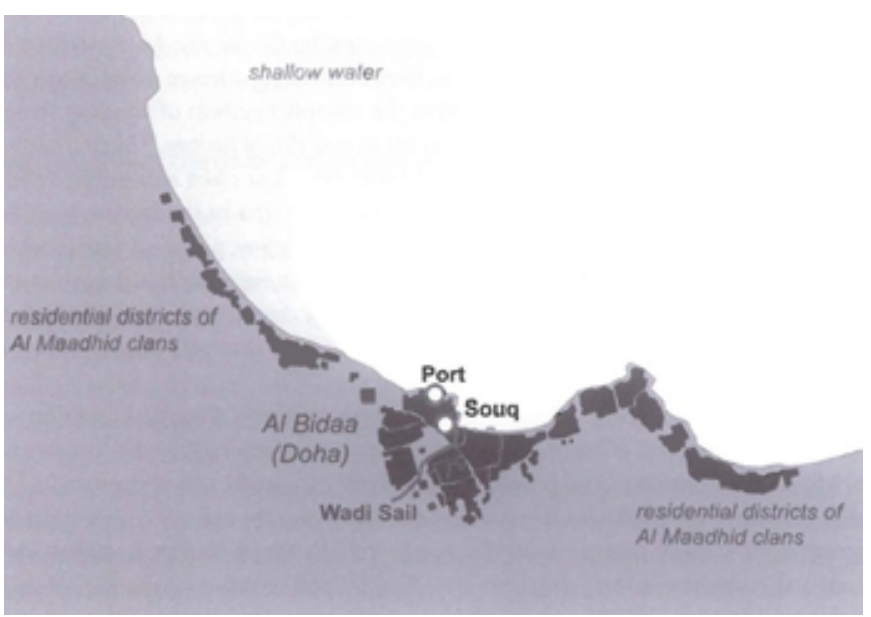

Figure 1: Doha's pre-oil settlements in the 1950s [1]

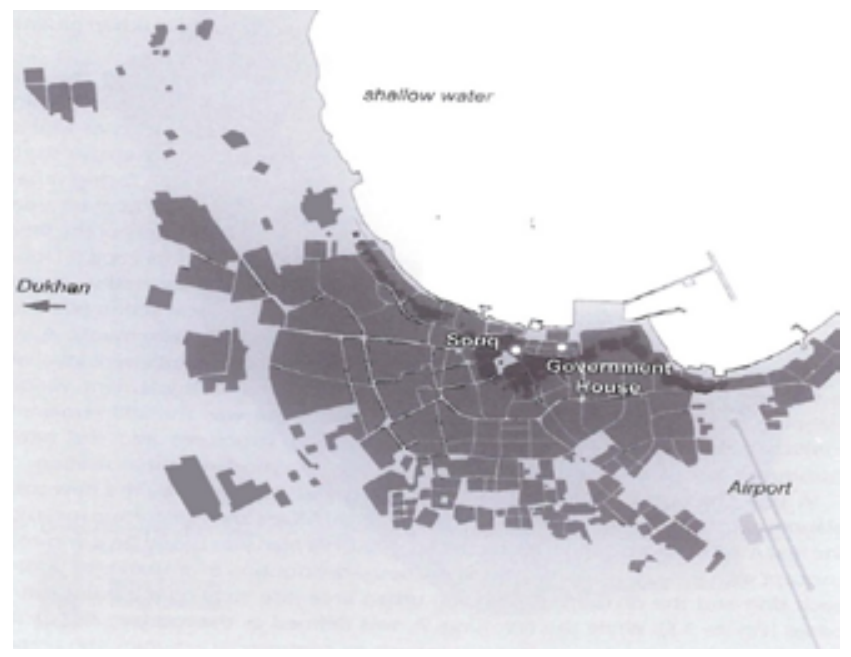

Figure 2: Doha's settlement areas in the 1970s [1].

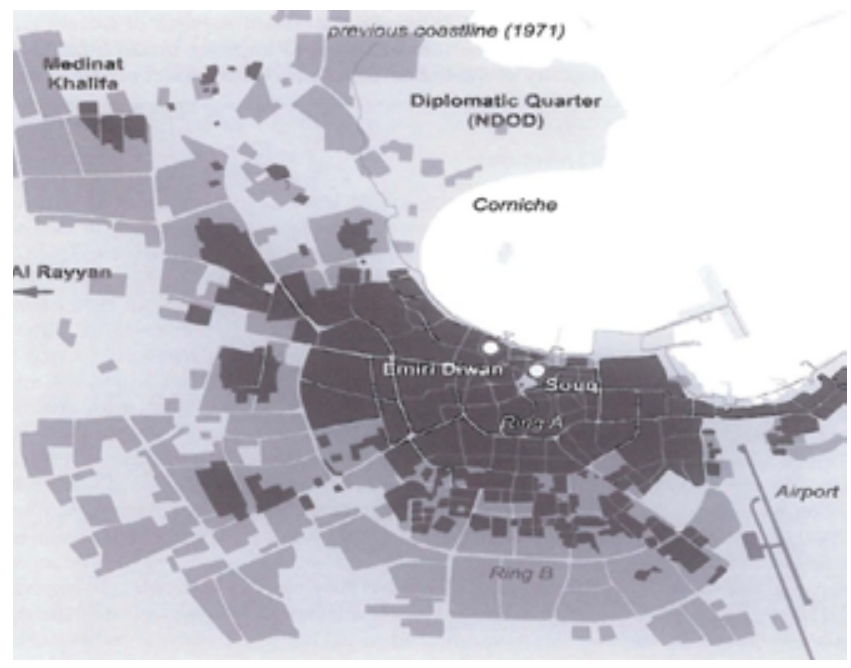

Figure 3: The settlement areas in the 1990s [1].

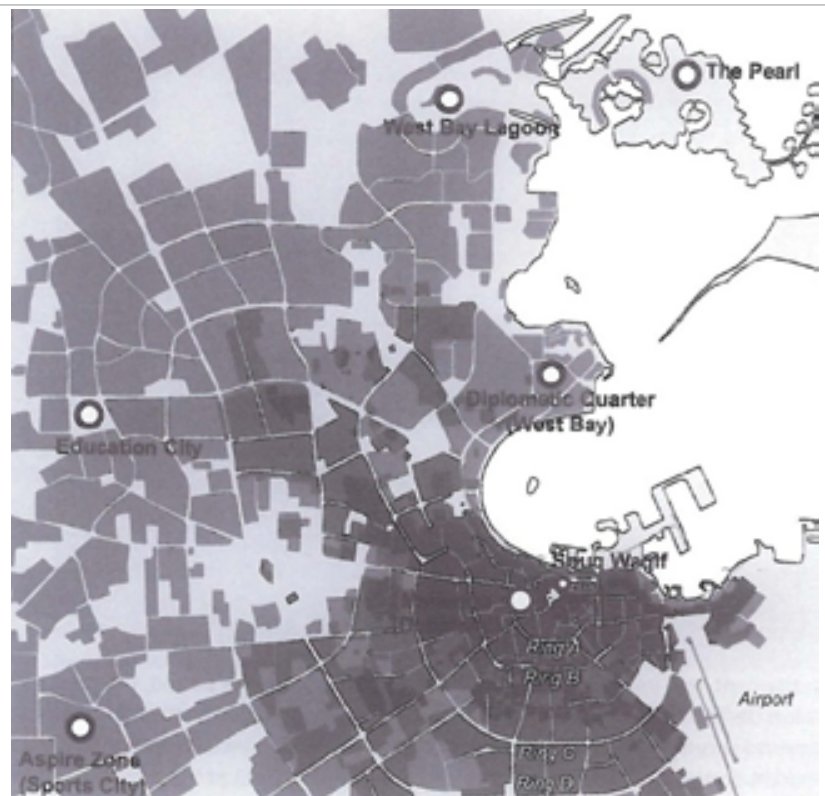

Figure 4: The past ten years settlement expansion [1].

Islamic architectural past: traditional architectural elements, such as façade of arches and domes, are integrated onto the modern built forms. The third category sees buildings displaying the essence of Islamic architecture and allowing for the modern building technology to be used as a tool in the expression of this traditional essence [7].

Doha is a city displaying with its districts and buildings a balance between contemporary and traditional architecture. Many of Qatar's heritage buildings, designed accordingly to the distinctive Qatari architecture character, are as magnificent as those designed with a contemporary architectural language. It is easy to identify the traditional district such the Souq Waqif (Down Town Doha) [8]. It is the district closer to Qatari culture. In the winding labyrinths of the Souq Waqif it is possible to find a variety of objects to buy, such as traditional clothes like abayas, and some of Doha's best restaurants where to dine. Souq Waqif is the real core of traditional local culture: an ideal place for people to meet for social purposes (Figures 5-7).

Not far from the Souq Waqif, it is also easy to find the contemporary business district called West Bay, which includes many modern buildings unlike other older districts of Doha. Some of the tallest skyscrapers in Qatar, such as the Al Quds Endowment Tower, are visible in this area. Among the many visible contemporary buildings, one of the most distinctive is the award-winning shiny and tall Burj Qatar (Figures 8-11).

On its side, during the nighttime hours, The Burj Qatar also projects calm orange and white light, which look magnificent from 'The Corniche'. The Cornice is a linear link with other radial connectors (previously also defined as 'the great connector' and 'grand curve'), which connects West Bay ('New Doha') to the Souq Waqif ('Old Doha'). It is a waterfront promenade, which runs for several kilometers along Doha Bay and provides a wonderful view of the bay. The curve of the cornice is the identifying motif of Doha: it celebrates the dialogue between new and old and between the land and the sea across the space of the bay. The dialogue established by the Corniche is essential to the identity of the city. This embracing open public space is interpreted as the 'Urban Majlis', the great gathering place, which holds the city together (Figures 12-14). 
Citation: Furlan R (2015) Livability and Social Capital in West Bay, The New Business Precinct of Doha. Arts Social Sci J 6: 116. doi:10.4172/21516200.1000116

Page 3 of 11

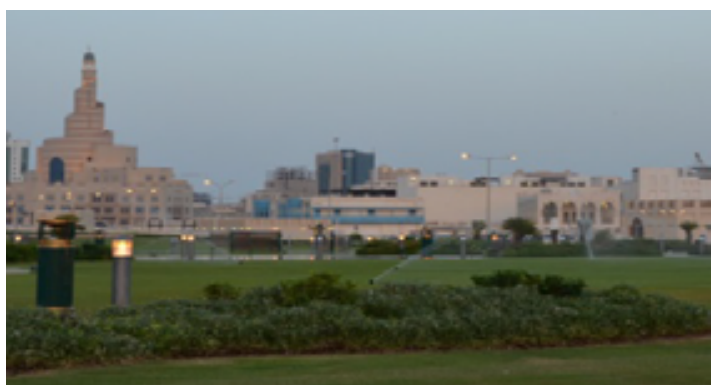

Figure 5 : Views of the Souq Waqif (Photos from the authors).

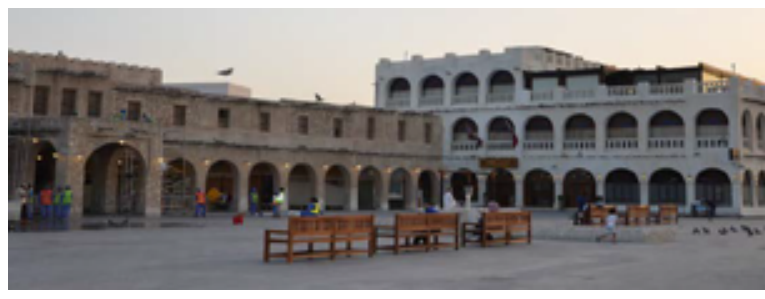

Figure 6 : Views of the Souq Waqif (Photos from the authors).

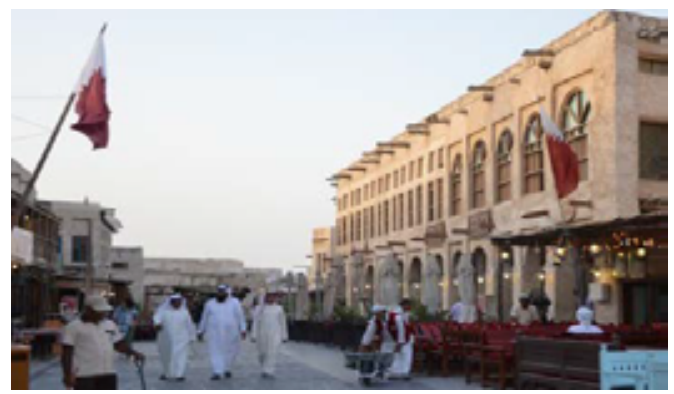

Figure 7 : Views of the Souq Waqif (Photos from the authors).

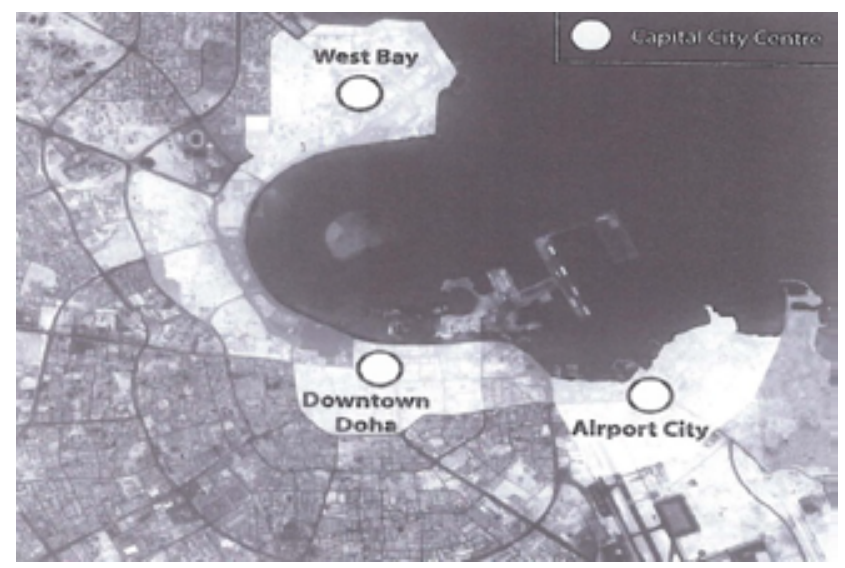

Figure 8: The Capital City Precincts [1].

This paper focuses on the neighborhood of West Bay, which, as anticipated, is considered the most modern area of the most prominent districts of Doha. The exploration of this research study centers on the social activities of human settlements as a mean to enhance social capital and consequently livability. The research question is concerned with understanding whether and the extent to which livability can be enhanced in the built Environment of West Bay or how the built environment can be humanized in order to make it more livable. The human settlement incorporates patterns of human behavior and it is the arena for human activities. By exploring the need of activities performed and to be performed by inhabitants, it is possible to understand how to shape the built environment in order to allow the users to perform the specific activities dictated by their social needs. In turn, the findings will provide an input for the implementation of the urban and architectural design in order to enhance livability in West Bay.

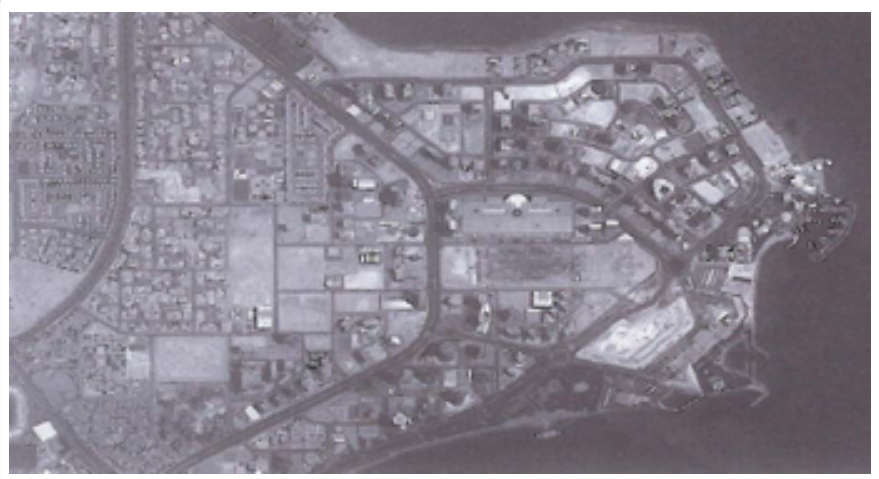

Figure 9: Satellite view of West Bay's waterfront [1].

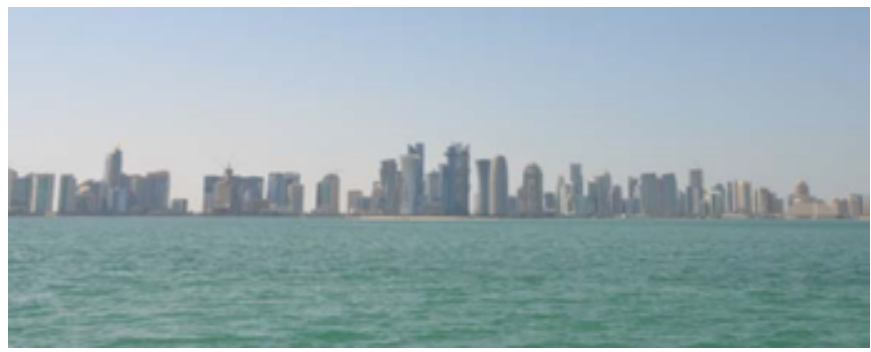

Figure 10: Views of West Bay (Photos from the authors).

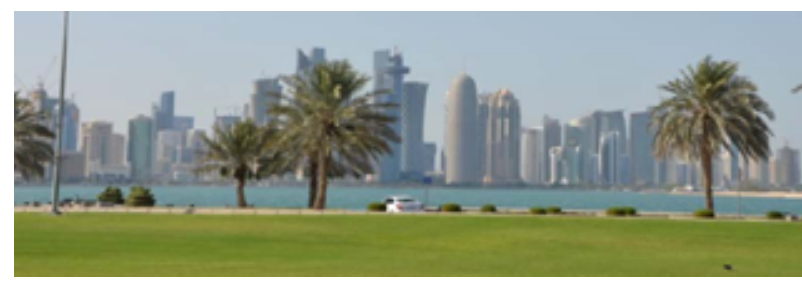

Figure 11: Views of West Bay (Photos from the authors).

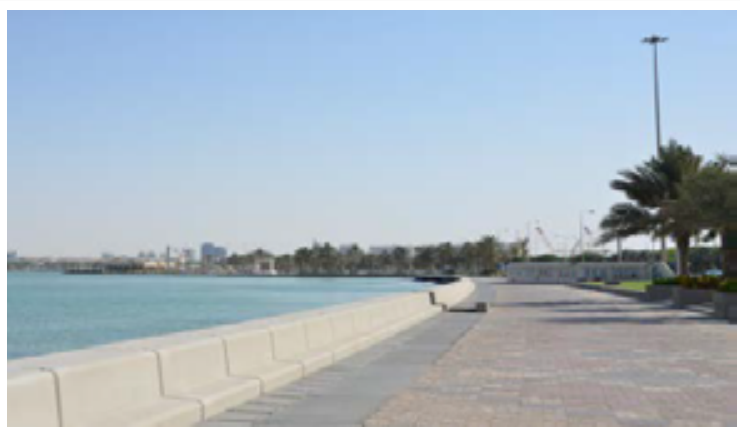

Figure 12: Views of the Corniche (Photos from the authors). 


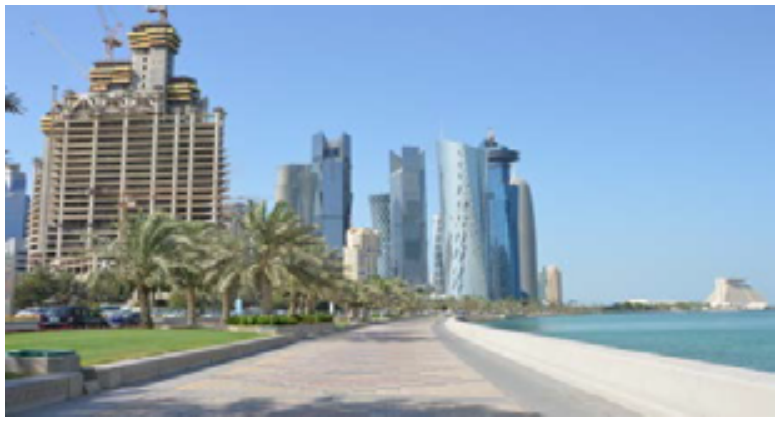

Figure 13: Views of the Corniche (Photos from the authors).

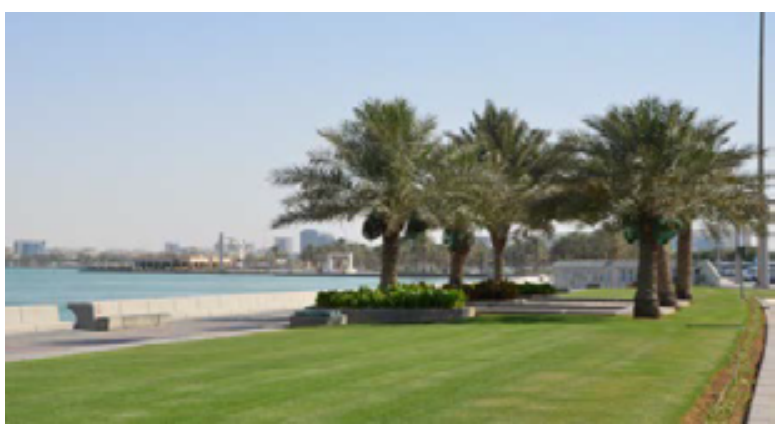

Figure 14: Views of the Corniche (Photos from the authors).

\section{Background}

\section{Urban design: livability and users' needs}

'Urban designers can make a strong, positive difference in the lives of the people on whose behalf they work... Urban designers can only make such a difference when they understand the forces that shape people's lives-and, in turn, the places they inhabit' [9].

In modern days, cities have hosted iconic buildings, which have often become the manifesto of the star-architect/celebrity. As highlighted by Amos Rapoport, grand-elite or iconic buildings might have a strong meaning but often they are sculptures representing an isolated context rather than being integrated within the existing urban fabric, which is the result of an historical traditional process, or, as Ron Kasprisin stated, of culture, space and time.

'Culture, space and time are the 3 components that interactively shape the human settlement or built environment. This interaction manifested through the functionality of the built environment produce 'meaning' which are expressed or embedded in the built environment' [10].

Buildings should contribute to implement physical and social landscapes, to shape settlements in response to people needs and finally to integrate built forms within the built environment with the final purpose to express the interaction between people and environment, which finally gives value and identity to the place where people live [11]. The multifaceted discipline of Urban Design is vital for shaping our cities, which are not only vehicle for creating iconic objects d'art, but, namely, places where people live in and perform activities, which are expression of their needs. Therefore, places shaped with this framework can be vehicle for livability $[9,12,13]$.

This means that nowadays, urban designers are no longer required to simply focus on the implementation and decoration of the spaces between built forms, namely town squares, streetscapes, parks, pedestrian and transport networks. Rather, the contemporary role of the urban designer is to investigate and understand the essential and necessary relationship between physical form and the social life of the inhabitants of any space in order to shape settlements and built environments. This will enhance livability and/or facilitate people to carry on social activities dictated by their needs $[14,15]$.

\section{New urbanism: communities, cars and walkability}

'Cities exist because humans are social beings, variously tribal, communal, and mutually supportive... with the emergence of surplus economies, hierarchical societies appeared and supported the growth of villages, then towns, and, finally, cities' [9].

Contemporary architects and urban designers shared this view: socio-cultural values are embedded in the built environment and at the same time socio-cultural differences in users' way of life can influence spatial environments. This principle prompted planners and architects to propose a new spatial and architectural vocabulary for the development of suburban communities. In the 1980s, the planning of Seaside, a community on Florida Panhandle, became the spark for a new movement called New Urbanism. The new model was called "traditional neighborhood developments" or TNDs. New urban designers and planners applied the approach of designing and neighborhood and dense urban centers around the needs of car. Over the following two decades, American cities were redesigned and planned in order to become car-oriented settlements. Afterwards, (in the mid-1990s) scholars recognized that the New Urbanism Movement triggered the birth of not sustainable car-dependent suburbs and namely sprawls. This was also caused by the lack of consideration to walkability, proximity of public transports, bicycle networks and public realm in general. This is well explained by Jeff Speck. In his words:

'We've known for three decades how to make livable cities-after forgetting for four-but the typical American city does not reflect this knowledge, as it is still inadvertently being designed by a public works department that, worshipping the twins gods of Smooth low and Ample Parking, has turned the downtown into a place that is easy to get to but not worth arriving at. We no longer need to reform urban design; we need to reform the relationship between urban designers and those who build the city' [9].

In turn, after recognizing this problem, scholars were driven to shift the focus from car-dependent communities to neighborhood with enhanced walkable and bicycle networks. Many Americans who were asked where they would like to leave, preferred dense, small and compact urban communities, walkable settings, which use energy far more efficiently and generate far fewer emissions per capita than existing car-dependent suburbs. This perspective influenced the vision of planners and architects for the development of new communities $[9,14,13]$. Therefore, the forces shaping 21 st century Urbanism were now based on using carbon reduction, creating greener cities and suburbs to improve quality of life and/or livability. 21st century Urbanism advocated strategies for recentralization, in order to reduce or stop sprawls in the cities [16].

'The incidental exercise that we have eliminated from our daily lives has had major negative implications on environmental pollution, mental health, and socialization, and especially on our own strength, activity levels, and obesity level. While we focus on obesity, activity level is of equal importance. The estimated weight difference between people living in sprawling areas versus more dense areas is on average, about six to 
seven pounds. Of that weight gain, it is likely that half or at least a third, are the result of lower activity levels' [9].

In this era, urban designers became more sensitive toward the rediscovery that we can create buildings and neighborhoods which can contribute to implement health among the population. Designers highly considered the design of fine streets, attractive parks, active public spaces, and successful green neighborhood that, is brought together in one city, in order to create a magnificent livable urban place.

'Green building is important, but Americans are rapidly learning that they can do far more to reduce their carbon footprint -and make a far more significant contribution to addressing global climate changeby supporting smart growth policies that promote walkable, mixed-use communities offering a range of transportation choices' [9].

This period marked also a return to greener, denser, more livable urban neighborhoods, with more walkable and bicycle networks in order to reduce sprawls of the urban fabric and implement the smart use of the resources. In addition, urban designers embraced the preservation approach, willing to reclaiming historic and traditional principle for the construction of new neighborhoods. City streets are now claimed as public places and it is recognized that public streets should support more social functions than simply moving vehicles. This concept has been widely auspicated in the 80 s by the urban designer Donald Appleyard, who stated that designing livable streets is necessary to reduce traffic. In his view, pedestrian activity contributes to increasing neighborhood livability and a sense of community. Based on this approach, by the late 2000s, many cities and states invested funds for redesigning livable streets, used by pedestrians, bicyclist, as well as automobile users $[9,14]$.

In conclusion, New Urbanism describes its mission as 'the revival of our lost art of placemaking ... essensially reordering of the built environment into the form of complete cities, town, villages, and neighborhood - the way communities have been built for centuries around the world' [9]. The main purpose of the movement is to create more walkable, people-oriented precincts versus car-oriented and dependent communities.

\section{The principles of 'sustainable urbanism'}

Previously, the American pattern of a community was shaped around the suburban single or detached house with a yard around the property and a carport sheltering at least two cars. This private transportation system allowed single families easy access to jobs, to commercial areas, recreation, and various facilities served as a near universal model for shaping American communities. This typology was the physical expression of self-confidence, independence, professional and social success $[9,14]$ Also, new Urbanism proposed a multi-faceted philosophical and applied approach to design and planning public spaces (also called Placemaking), promoting people's health, happiness, and well-being. In addition to New Urbanism and Landscape Urbanism, sustainable urbanists encouraged the development of smart and compact communities, in order to avoid sprawls, which became inevitable under the New Urbanism period.

'What does urban design need most? In a word, collegiality. Urban design is only possible when people from various disciplines and professions, and from arts and sciences, agree to work together. In the past, when it was civic design, it focused on the public realm. It was sponsored by civic association and enriched by civic art. Today the field of urban design is unbounded, intellectually and physically. Architecture extends from room to region' [9].
The designers, which belonged to the newborn movement, proposed principles, strategies, and process for the urban design of comprehensive communities. These core principles defined to guide urban design for the new era were developed on previous foundationtheories. (1) The main goal, which is also considered the first principle of the movement, became 'enhancing livability' by offering the broadest potential individual choices for living healthier. The previous 1960s' model, based on drivable communities offering limited options for living, working, shopping, and entertainment, was not appropriate anymore. Walkable networks could offer access to a broad range of life choices in compacted communities and therefore this urban pattern became an exemplary of enhanced livability [17-19].

The first principle represented a key step toward 'creating a greater sense of community', which is considered the second principle (2). The sense of community should be enhanced in order to promote engagement, participation and integration among users. These two initial principles are prerequisites for the following principles: (3) expanding opportunity and (4) promoting greater equality. The goal is to create more economically competitive cities, made of walkable environments. On contrast, sprawls and development of road have undermined cities' ability to provide an economic competitive arena. Also, built environments should be developed in order make society more equitable. The last core principle is (5) fostering sustainability. These principles should be the foundation for the future approaches to the way the urban fabric of cities is developed $[9,14,18]$.

\section{Urban sociology: the humanization of the built environment}

A renowned sociologist, Putnam highlights that the way we design and build a macro-scale urban setting where communities reside can have a deep impact on the degree to which people are involved in those communities (neighborhoods). He stresses that the surrounding built environment, can contribute to enhancing social interaction among the population and therefore enrich a sense of community, [20-26]. Social scientists and urban designers share Putnam's view and stress that the planning of a city has an impact on the way people live in the city. Emphatically, the way the city and its sectors are planned has a deep impact on the way people use the city, live their daily lives and carry on their social activities. Besides, creating an environment that allows to carry on social activities means to enhance social capital and livability, or broadly to humanize it [27]. As highlighted by scholars, a humanized built environment is the manifestation of the 'forces that shape people lives'... 'Urban designers can make a strong, positive difference in the lives of the people on whose behalf they work... Urban designers can only make such a difference when they understand the forces that shape people's lives-and, in turn, the places they inhabit' [9].

In addition social researchers argued that, in response to the recognition that urban designer, planners, architects, builders and developers, in their pursuit of economic and technological efficiency, have not considered the human context in the design of spatial environments in the past two decades, built environments should be designed and implemented as per users' specific needs, which are expressions of culture as way of life. This new approach to both urban and architectural design, arguing the need to create physical designed environments responding to occupants' specific needs, inspired the parturition of the 'social design movement' [28]. Cause of this innovative approach, multidisciplinary practitioners became more sensitive to the human context of the designed built form. Namely, in the 1980s, researchers from various social sciences conducted extensive research and gained insights into the relationship between human context and designed physical environments. Notably, urban sociology, a discipline 
emerged during this time, aimed at studying the relationship between human behavior (and/or activities) and the spatial form of the built environment, with the purpose to reveal how human activities are projected onto physical environment [27]. In addition, social scientists argue that the designed physical space, ranging from macro-scale level built environment (big-scale cities) to micro-scale built form (smallscale buildings), influences and, at the same time, is influenced by the behavior and/or activities of its occupants. Additionally, they state that it is virtually impossible for any human behavior to reside outside of cultural influence, because behavior and culture interact continually throughout development. Therefore, they emphasize that while the focus of investigation is the relationship between spatial environment and human behavior, the role of culture as a way of life must also be explored. More specifically, urban sociologists argue that an analysis of human behavior and/or activities can provide an understanding of how the built environment should be shaped in response to its users' specific needs, which are an expression of culture as a way of life [29-38]. Therefore, urban sociologists aim to apply their theories and research methods to the urban design process, with the purpose of creating designed physical environments responding to users' specific needs or simply to humanize them [39].

My own view is that architecture is a reflection of behaviour or the use of space which, in turn, is a reflection of culture; the use of space is the result of highly culture-specific and at times temporal-specific designs [40].

Urban sociology is the most relevant discipline to the context of this research study, the West Bay case study, because the objective is to understand how the fulfillment of users' cultural needs can contribute to implement the design and construction of the built environment of the users. This in turn would contribute to the humanization of the spatial environment or to make it more livable. These insights are significant in order to construct a conceptual framework to understand the extent to which the built environment of West Bay should be implemented in response to its users' cultural needs.

\section{Methods for Collection of Data}

'Urban designing is an argumentative process in which participants in it learn as they go along. They learn about goals and means as perceived by different stakeholders, they learn from the evidence that each provides for its views' [23].

To understand how livability can be implemented in the business neighborhood of West Bay, visual and oral data was collected and analyzed. The collected data focused on the activities performed within the district. Visual data was collected using four methods: (A) cartographic sources; (B) historic maps (the process of formation was deduced from their comparison); (C) photographs and (D) site observation. Oral data was collected though a survey, which was conducted from February to March 2015 in eight high rising residential towers in west Bay. Six hundred households were delivered a survey form to be filled in from the receptionist of the residential towers. The cover letter asked that the survey to be completed and returned by one adult member of each selected household to the operator at the reception within two weeks from the date it was received. A total of 390 surveys were returned, for an overall response of $65 \%$. Three sets of focus group interviews in selected residential complexes were also performed in April 2015 to discuss perspectives and experiences of householders [40-47].

\section{Findings}

From the data collected from the survey and from the analysis of perspectives, experiences and responses gleaned relating to the extent to which livability can be enhanced in West Bay, it emerged that the built environment should be strategically implemented in order to enhance livability. The following presentation of the findings is structured into five categories, following the analyzed responses. These categories contribute to develop a strategy for creating and enhancing livability in the West Bay district.

\section{Mixed-use and compact neighborhood}

Participants highlighted that one of the most important advantages in living in West Bay is the opportunity for a person to live close to his or her place of employment. Most participants stated that they choose to reside in West Bay due to the vicinity to workplaces. The reduced distance between housing and workplaces is an aspect, which has a significant implication for creating livability because it contributes to the following benefits: saving time on commutes; contribute to reduce traffic congestion; saving expenses for transportation. A negative aspect is the one related to the lack of small shops in the neighborhood. The nonexistence of a sufficient combination and integration of residential and commercial uses was emphasized, namely seen the compactness of the development. Typically it was highlighted that mixed-use development means complexes including a mixture of commercial areas such as small shops, storefronts or restaurants at the lower floors with apartment on upper levels. The mixed-use pattern can offer residents an excellent opportunity for short commuted to walk and convenience shopping. Also, it was pointed out that the resulting increase in walking, and therefore decrease in short trips by automobile, could be of great benefit to individual health, reduce further traffic congestion and energy consumption for transportation.

Residents perceived the residential towers where they reside more as hotels or places for temporary permanence, rather than permanent long-term dwellings. This typology lacks the capability of creating a permanent sense of place specific to a site or community. Finally, residents suggested that urban designers should revive principles of traditional neighborhood into a modern development such as West Bay: mixed use and compact development pedestrian and bicyclefriendly environments. Otherwise, the neighborhood becomes a commuter belt or a dormitory town (Figures 15-17).

Public Realm, streetscapes and social network, It was commonly stated that the lack of social networks or connections among the neighbors does not enhance a sense of belonging to the community. Participants pointed out that in West Bay the sense of community is also missing because of the lack of public spaces where people can easily interact. Public spaces -particularly lively streets and squares- among buildings enhance livability and help to animate the neighborhood. Open spaces have the role to make people passing near or stopping by and feel them welcome. This can be enhanced by landscaped squares, street furniture and other public-realm amenities that meet livability goal. Additionally, the enhanced public spaces can support the sense of belonging to the community. It was emphasized that there are only private gated car-parks among the buildings, as shown in the images below (Figures 18-20).

Participants highlighted that; cause of this pattern, West Bay is hard to navigate, hard to cross the road and hard to feel at home. The buildings enclose many comfortable facilities but at the same time they seem alien, similar to one another. For example, participants highlighted that at the West Bay end of the Corniche there is Sheraton Park. Many participants spend some time on weekends or in the evening at the park with a book, a laptop or simply to relax (Figures 21-23). 


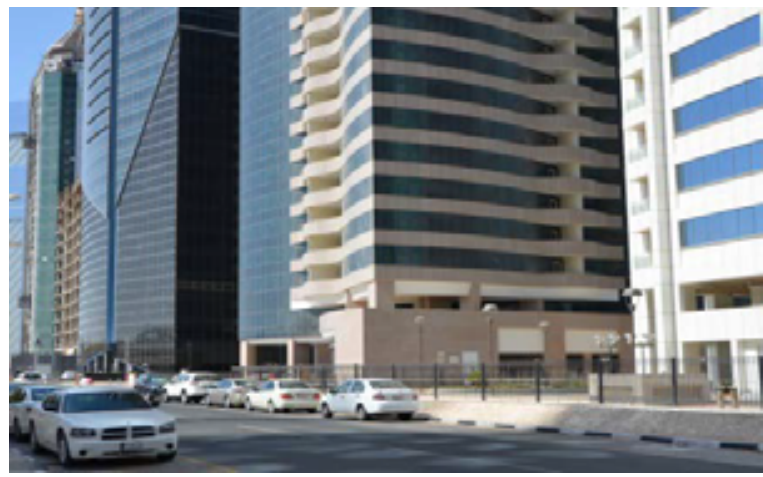

Figure 15 : Residential towers in West Bay (Photos from the authors).

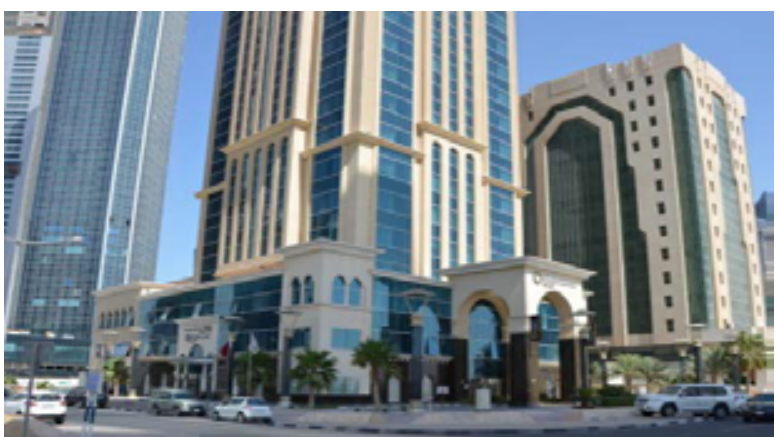

Figure 16 : Residential towers in West Bay (Photos from the authors).

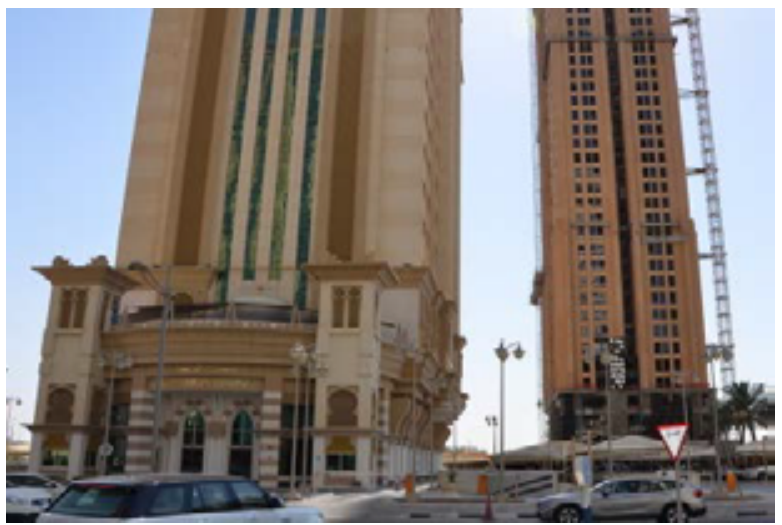

Figure 17 : Residential towers in West Bay (Photos from the authors).

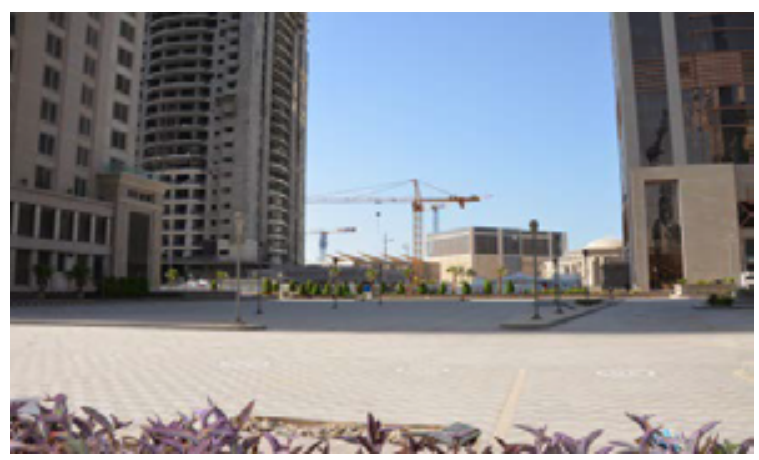

Figure 18 : open spaces between buildings utilized as carpark (Photos from the authors).

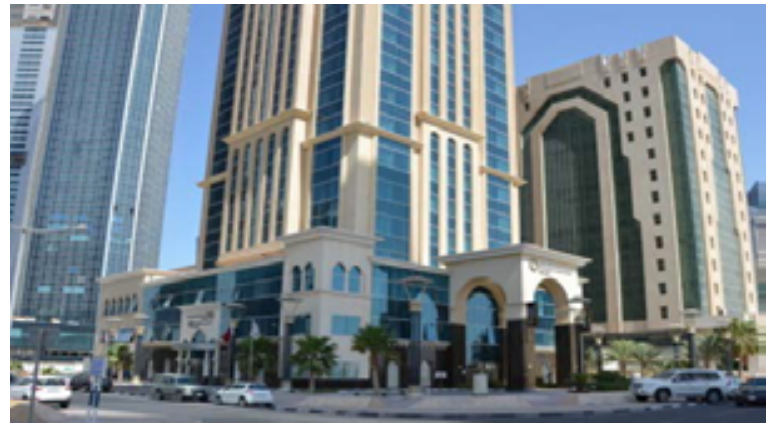

Figure 19 : open spaces between buildings utilized as carpark (Photos from the authors)

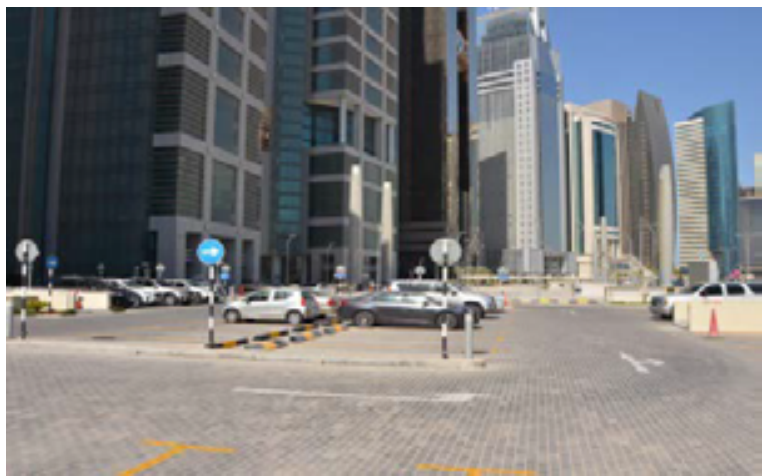

Figure 20 : open spaces between buildings utilized as carpark (Photos from the authors)

Aniza Park is another park located in West Bay which was often mentioned. Participants defined it a 'family park' conveniently located in West Bay. Unfortunately, the park is not connected to the district via pedestrian or bicycle network (Figures 24-26).

Open spaces like small parks or shaded town squares, shop-fronts and a greater sense of enclosure are features which would make West Bay in the future a more welcoming place. Also, parking could be rearranged in order to add a layer of human scale and animation, to bring the street to life and to finally enhance livability. A suggestion was to link West Bay's 'spine' to the Corniche and transforming it into an urban boulevard, which could become a major pedestrian connector.

\section{Public transport}

Households in this area stick to private vehicles. They sated that rarely there are just a few persons waiting for the bus (especially in the summer heat and humidity). Also, the case of Dubai was mentioned as a reference to be kept into consideration for the development of public transport in West Bay. It was highlighted that Dubai has both a monorail and metro, used by locals and expats. This system is popular and expanding in UAE. This is the future for Doha's new metro, which definitely will contribute to enhance livability. At present, the only public transportation mode in the West Bay district is represented by bus services, Karwa, which has well-distributed routes all over the city of urban Doha, and the West Bay bus, which connects inner parts of the area to the external Karwa stations.

\section{Walkability and pedestrian safety}

West Bay is a new neighborhood where several areas towers are still under development and construction. West Bay is a difficult area 
Citation: Furlan R (2015) Livability and Social Capital in West Bay, The New Business Precinct of Doha. Arts Social Sci J 6: 116. doi:10.4172/21516200.1000116

Page 8 of 11

to explore or go around by foot, namely during the vicious summer months, because there are not sufficient pedestrian network, footpaths, sidewalks and other pedestrian rights-of-way. This makes West Bay a neighborhood for car drivers, and definitely not for cyclists or pedestrians. Tenants suggested making the paths and promenades as convenient and comfortable as possible, also through diagonal paths among buildings and private-gated car parks, connection with adjoining properties, where it is feasible. There is a lack of street connectivity and pedestrian are forced to walk besides the streets when footpath are available and namely around buildings. The needed infrastructural factors required include footpaths, safe pedestrian crossings or crosswalks, shaded street furniture allowing people to stop and find shelter, namely in summer time. The implementation of the built environment with these factors would enable to have a truly walkable community.

It was highlighted that pedestrians are particularly vulnerable in Qatar, in general, and in West Bay too. Accidents to pedestrian while crossing the street are common. This is due to ongoing construction work, few sidewalks and an abundance of speeding vehicles. This proves that at this stage West Bay is still not a pedestrian oriented neighborhood. Participants also highlighted that the public authority Ashghal have issued significant funds to be invested on safety upgrades, better street signage and construction of additional pedestrian overpasses (Figures 27-29).

\section{Bicycle network}

While many argue that the culture and climate do not align with a cycling lifestyle, many householders living in West Bay believe that Doha has the potential to become a cycle-city. The city is flat and already now scattered bike lanes exist. While temperatures reach $45^{\circ}$ Celsius in the summer, from October to May the weather is quite pleasant. It was highlighted that pedestrians are prevalent in the Souq, and also enjoying evening walks along the Corniche. Nevertheless in the meantime, people rely on their cars; in part because city buses are unreliable and infrequent, and distances are sprawling.

It was emphasized that in Dubai, which has the same climatic conditions of Doha, cycling has gained some ground. The municipality has invested in better cycle paths and related facilities (public showers, etc.) Cycle groups organize weekly trainings and excursions. While these are primarily longer distance rides and semi-pro trainings, these events have brought visibility to the sport. In efforts to curb obesity and diabetes, the city's cycle paths are advertised for families and recreation. By comparison, encouraging 'seasonal recreational biking for health' in Doha, could perhaps work; or a system of rental bikes connecting Doha's highlights (e.g. the Corniche, the Souq, the Islamic Art Museum).

\section{Conclusions and Discussion}

As mentioned, Central Doha sits on the Corniche Bay. Along the Corniche, a walking path shaded by green spaces separating pedestrians from the cars stretches $10 \mathrm{~km}$, connecting East and West Doha, the old down town (the Souq Waqif) and the prestigious contemporary West Bay Business District. The massive urban development of the area started in 2003 and it is presently ongoing. West Bay became the first high-rise district in Doha (Figures 30-32).

High-rise buildings or skyscrapers were originally built in the United States. Afterwards, this phenomenon, which was mainly due to the increase of urban population and scarcity of urban land, spreaded out in many Asian metropolis. Nowadays, world widely globalization and rapid urbanization require urban development's characterized by high-rise buildings typology, mainly as symbols of globalism and economic prosperity. Practitioners usually emphasize the design

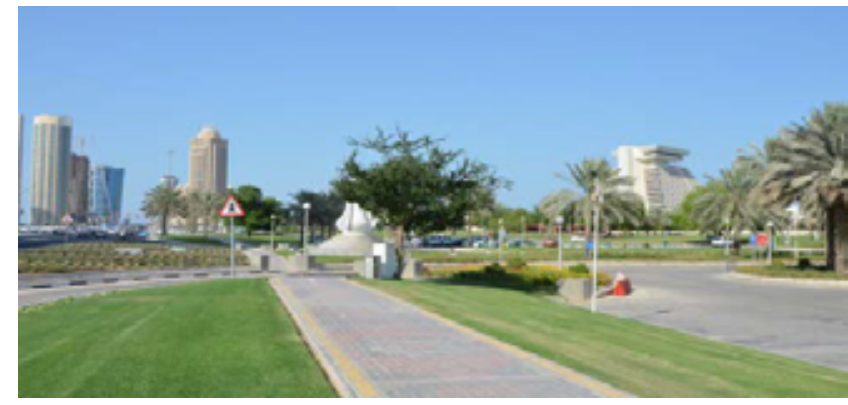

Figure 21: Views of Sheraton Park (Photos from the authors).

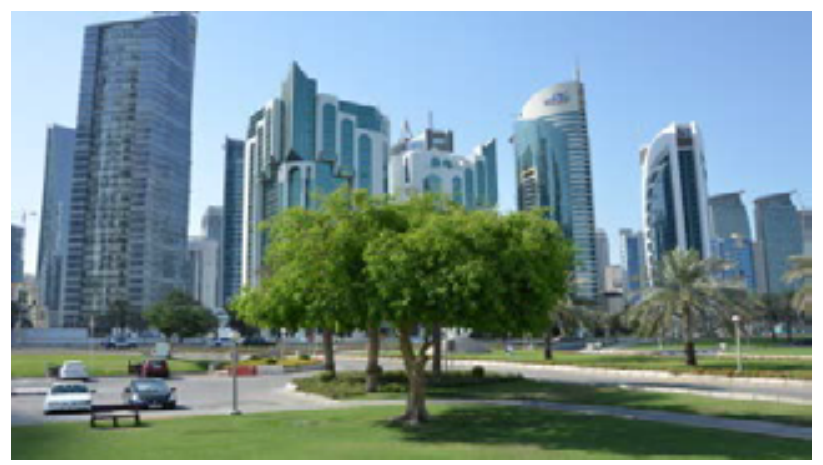

Figure 22: Views of Sheraton Park (Photos from the authors).

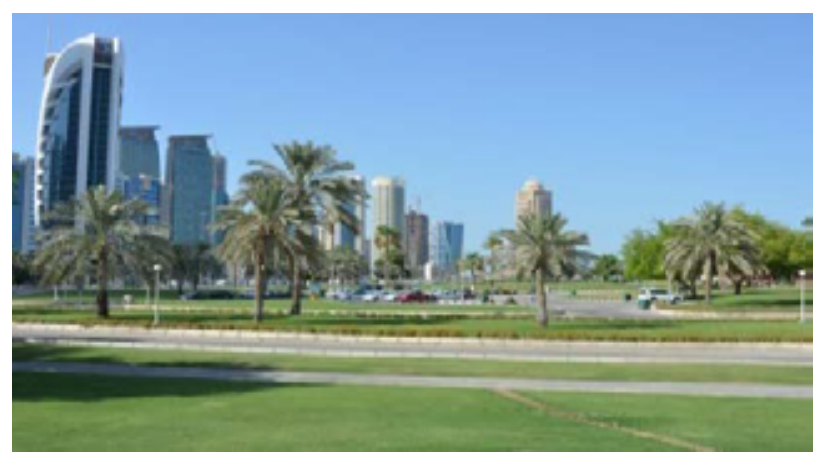

Figure 23: Views of Sheraton Park (Photos from the authors).

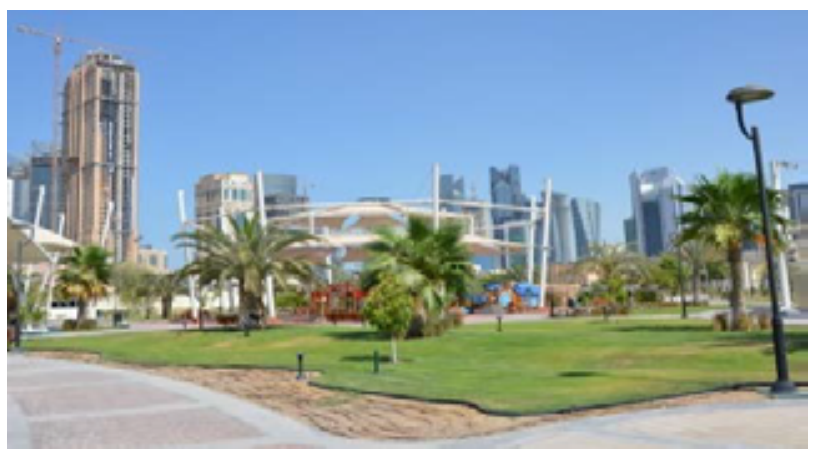

Figure 24: Views of Oniza Park (Photos from the authors). 


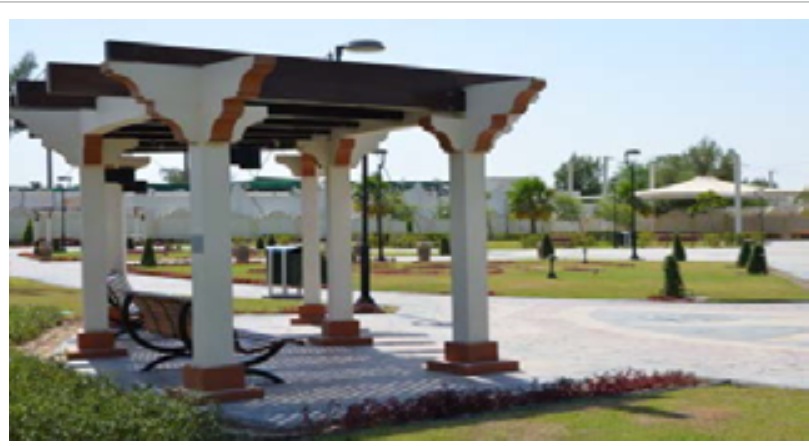

Figure 25: Views of Oniza Park (Photos from the authors).

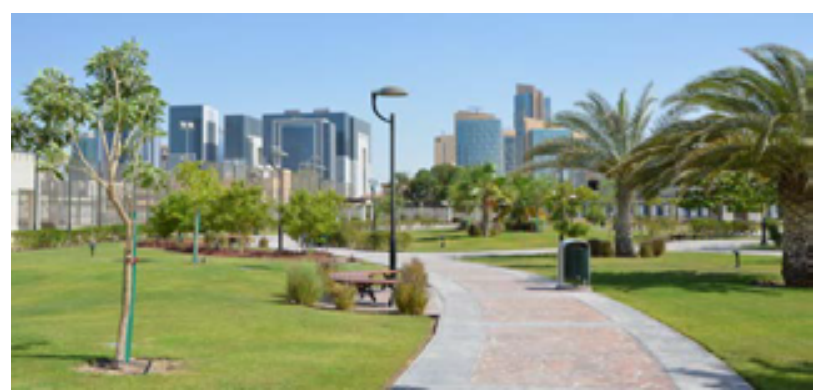

Figure 26: Views of Oniza Park (Photos from the authors).

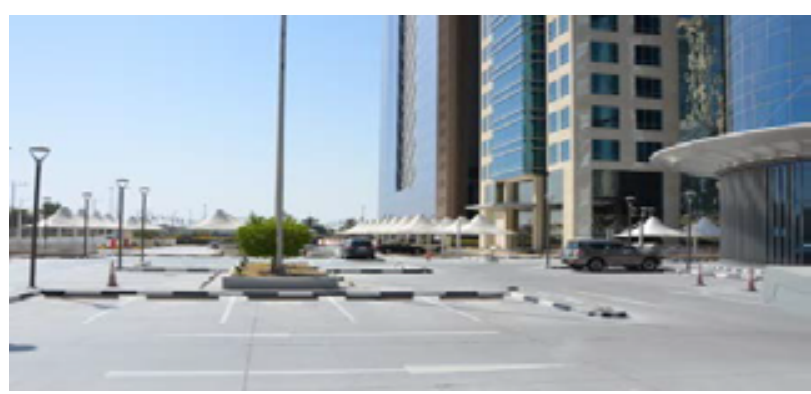

Figure 27: carparks surrounding the buildings (Photos from the authors).

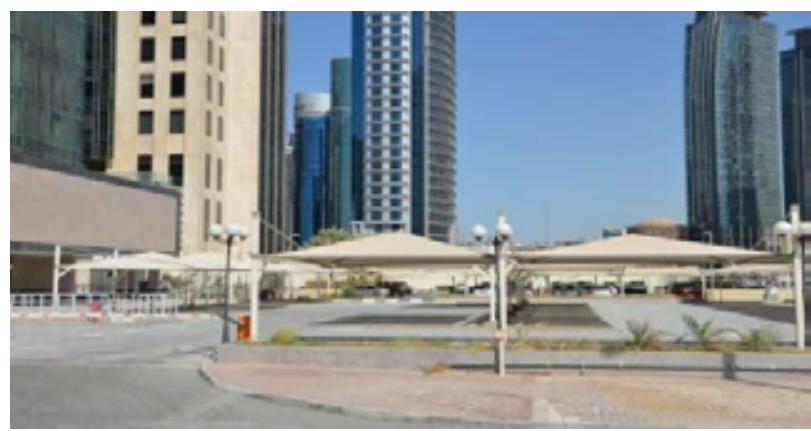

Figure 28: carparks surrounding the buildings (Photos from the authors).

benefits of the spectacular impact of iconic tall buildings on the skyline of cities. Lack of consideration is given to the way tall buildings are integrated with the ground level of the urban fabric. West bay is an example of this contemporary trend: it has been shown that the ground floor of high rise buildings is characterized by parking areas and security gates, lacking public realm spaces. This spatial configuration diminishes the accessibility to the area; the quality of life and finally livability of the district, where livability refers to the way spaces provide the arena for the development of social activities. Furthermore, the lack of services (public transportation), efficient pedestrian circulation and amenities (retail) within the residential towers does not facilitate the users to perform daily activities. This proves that (1) the built environment has a significant impact on the users' livability and (2) designed iconic high-rise buildings, which are the main features of eye-catching skylines, are not sufficient to contribute to successful urban sustainable developments. Livability criteria should be properly considered in the urban design of new district. An approach to implement or humanize these districts should be based on a collaboration strategy. This would include (A) an integrated urban design process, where multi-disciplined practitioners are collaborate involved in the final comprehensive design, (B) involvement of stakeholders and groupsusers in order to evaluate views and concerns. The proposed approach for the transformation of the district of West Bay into a more livable urban neighborhood is structured into five main phases:

1) Create compact multi-use urban areas with conveniently located schools, shops, and services, easily accessible at the ground floor of buildings. This would also facilitate an overall urban sustainability of the district, reduce the use of cars and promote social activities.

2) Create accessible shaded pedestrian-oriented public places or plazas between the buildings - instead of private gated car-park areas - to enhance outdoor activities and to encourage people to walk shop and dine. The development of an efficient footbridge network would facilitate linkages and/or connections between buildings and surrounding areas. Participants highlighted that they enjoy very much the cornice parks and walking, namely on weekends, and that public realm should be further developed to enhance social activities or capital among the population and around the city.

3) Developing an efficient public transport system connecting major urban nodes and sites in West Bay, in order to reduce traffic congestion, limit cars' usage and increase pedestrian and cycling movement.

4) Develop well-connected, convenient and safe walkways (pedestrian network). The Souk Wakif, which is always populated by people walking daily and nightly despite harsh yearly weather conditions, should be a reference in relation to walkability.

5) Develop cycling paths to provide dwellers efficient transport alternatives to driving and to enhance vibrant street life-recreational activities. Also, providing renting and/or sharing bikes and parking spots inside the district would promote the use of bicycles.

In the neighborhood, bicycle lanes and pedestrian sidewalks are found (although crosswalks are less prevalent). Similarly, public transport systems are already under construction and will be completed

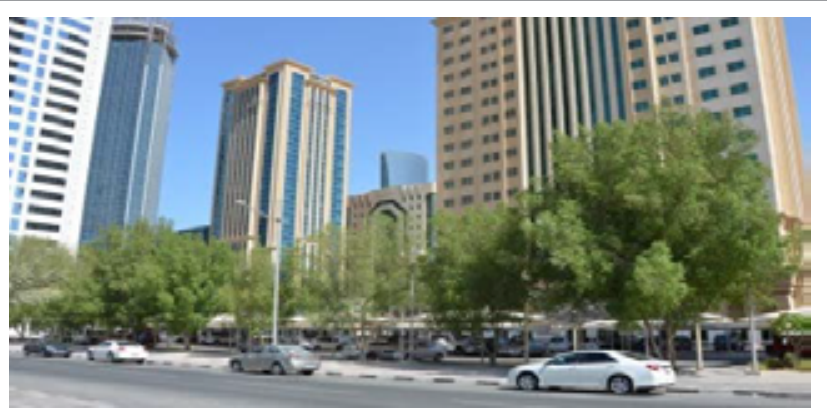

Figure 29: carparks surrounding the buildings (Photos from the authors). 
Citation: Furlan R (2015) Livability and Social Capital in West Bay, The New Business Precinct of Doha. Arts Social Sci J 6: 116. doi:10.4172/21516200.1000116

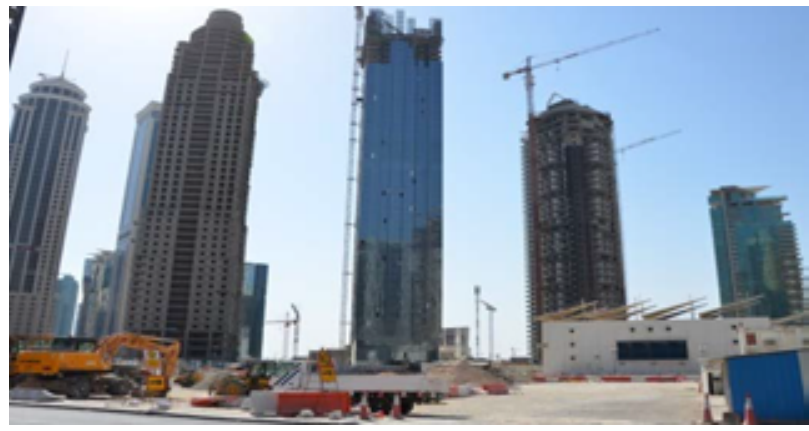

Figure 30: New developments in West Bay (Photos from the authors).

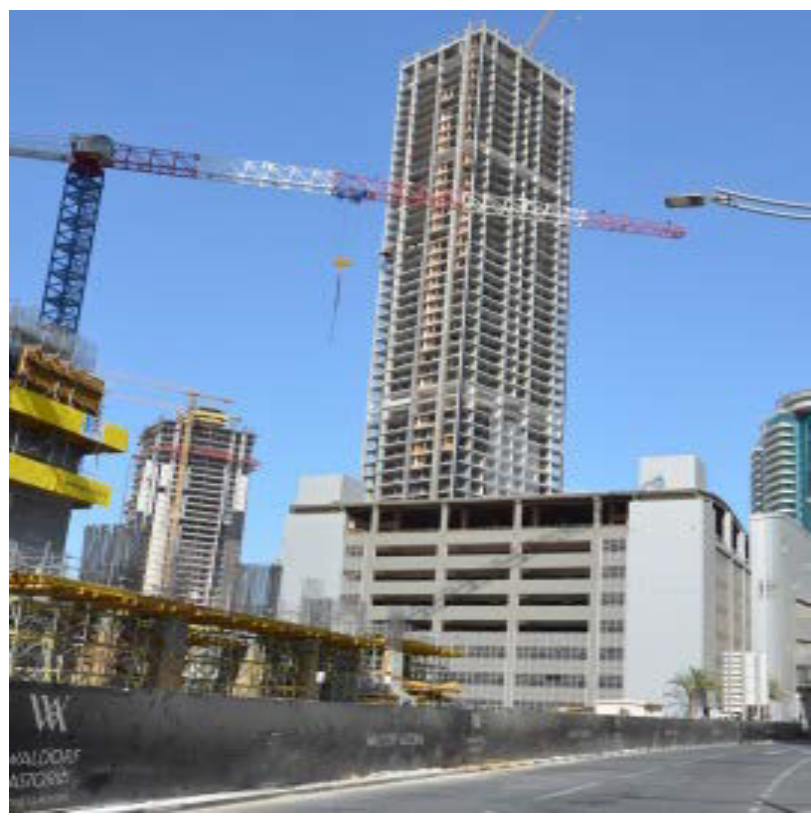

Figure 31: New developments in West Bay (Photos from the authors).

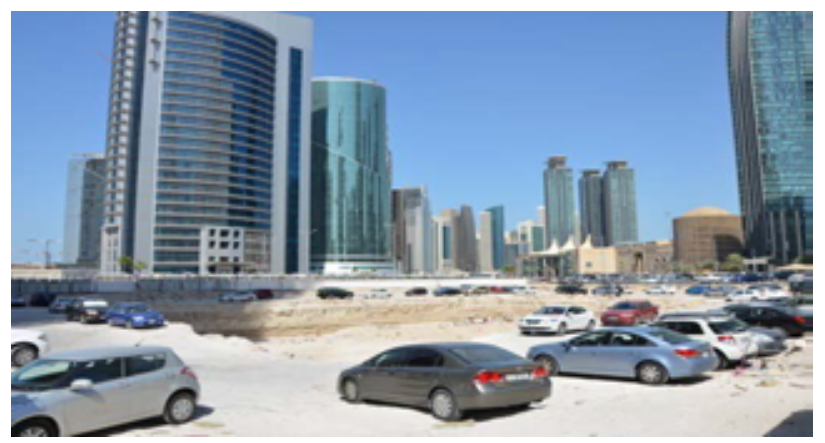

Figure 32: New developments in West Bay (Photos from the authors).

by 2022 for the World Cup event. It is also recognized that the city grows and changes, policies and infrastructure are continuously drafted and approved by authorities to implement the development of public realm, walking and cycling networks and public transport systems: for example, an extensive cycle route and pedestrian network are already planned throughout the city. These strategies for intervention approved by local authorities will have many benefits for the inhabitants: tackle obesity, improve quality of life in their public spaces, and reduce per capita greenhouse gas emissions. This will contribute to the construction of a compact district within a dense city, to the reduction of traffic congestion and to the restrain of urban sprawls.

Importantly all interviewees stated that West Bay is a very safe neighborhood. This has been highly appraised, namely in comparison to the contemporary loss of safety of several European cities, as highlighted by several participants. The standards of livability of West Bay are very high, but it is considered that there is space for improvement. The lesson from the past is that synergies among multidisciplinary practitioners and scholars should be implemented in order to not repeat the mistakes of the past. The final urban design product should the multifaceted result from the cooperation among multi-disciplinary consultants. Urban planners, architects, transportation planners and all multifaceted consultants should cooperate to deliver a comprehensive design, which enhances livability of the neighborhood and of the city.

\section{References}

1. Salama A, Wiedman F (2013) Demystifying Doha. Ashgate Publishing Limited, UK

2. Shaaban K, Radwan E (2014) Rebuilding the Transportation System in the City of Doha. Journal of Traffic and Logistics Engineering 2: 241-247.

3. Petruccioli A (2007) After Amnesia-Learning from the the Islamic Mediterranean Urban Fabric. Altamura Bari Grafica \& Stampa, Italy.

4. Benninson AK, Gascoigne AL (2007) Cities in the Pre-Modent Islamic World The Urban Impact of Religion, State and Society. Routledge, US.

5. Elsheshtawy Y (2004) Planning Middle Eastern Cities - An Urban Kaleidoscope in a Globalizing World. Routledge, US.

6. Hakim BS (2014) Mediterranean urbanism - historic urban/building rules and processes. Springer, New York.

7. Salama, Ashraf M (2007) Contemporary Qatari Architecture as an Open Textbook. Archnet-IJAR, International Journal of Architectural Research 1: 112.

8. Maimani A, Salama A, Ashraf M, Fodil F (2014) Exploring socio-spatia Apsects of Traditional Souqs: The Case of Souq Mutrah, Oman. Archnet-IJAR, International Journal of Architectural Research 8: 50-65.

9. Brown LJ, Dixon, David, Gillham, Oliver (2014) Urban Design for an Urban Century-Shaping More Liveable, Equitable, and resilient Cities. John Wiley \& Sons, New Jersey, USA.

10. Kaspirin R (2011) Urban Design-The Composition of Complexity. Routledge New York, USA.

11. Bonnemaison J (2005) Culture and Space. Conceiving a new cultural geography. Tauris IB, London, New York.

12. Cervero $R$ (2000) Walk-and-ride: Factors influencing pedestrian access to transit. Journal of Public Transportation 3: 1-23.

13. Lang J (2005) Urban Design-A Typology of Procedures and Products. Routledge, United States.

14. Farr D (2008) Sustainable Urbanism-Urban Design with Nature. Wiley, United States.

15. Murzyn-Kupisz M (2013) Cultural heritage in building and enhancing socia capital. Journal of Cultural Heritage 3: 35-54

16. Carmona, Matthew, Tiesdell, Steve, Heath, et al. (2010) Public places urban spaces-The dimension of urban design. Routledge, New York, USA

17. Besser L, Dannenberg A (2005) Walking to public transit: Steps to help meet physical activity recommendations. American Journal of Preventive Medicine 29: $273-280$

18. Giuffre K (2013) Communities and Networks. Polity, UK.

19. Stevenson D (2013) The City. Polity, UK.

20. Ankerl G (1981) Experimental sociology of architecture: A guide to theory research and literature. Mouton de Gruyter-The Hague, Paris, New York.

21. Bourdieu P (1986) The forms of capital. In Richardson JG (Eds), Handbook of Theory and Research for the Sociology of Education. Greenwood Press, New York pp: 241-258. 
Citation: Furlan R (2015) Livability and Social Capital in West Bay, The New Business Precinct of Doha. Arts Social Sci J 6: 116. doi:10.4172/21516200.1000116

22. Cao, Xinuo, Handy, Susan L, Mokhtarian PL (2005) The influence of the built environment and residential self-selection on pedestrian behaviour.

23. Coleman JS (1988) Social capital in the creation of human capital. American Journal of Sociology 94: 95-120.

24. Foley DL (1980) The sociology of housing. Annual Review of Sociology 6: 457478.

25. Gans HJ (2002) The sociology of space: A use-centred view. City and Community $1: 329-339$

26. Putnam RD (2000) Bowling alone: The Collapse and Revival of American Community. Simon \& Schuster, New York.

27. Smith R, Bugni V (2003) Designed Physical Environments as Related to Selves, Symbols and Social Reality: a Proposal for a Humanistic Shift for Architecture. Humanity and Society 26: 293-311.

28. Sommer R (1983) Social design: Creating buildings with people in mind Englewood Cliffs, Prentice-Hall, New Jersey.

29. Blier S, Preston (2006) Vernacular Architecture. In Tilley C, Webb K, Kuchler S Rowlanda M, Spyer P (Eds), Handbook of Material Culture. Sage Publications, London pp: $230-253$

30. Oliver P (1997) Encyclopedia of Vernacular Architecture of the World Cambridge University Press, New York.

31. Oliver P (1997) Kinship and Residence Encyclopedia of Vernacular Architecture of the World. University Press, Cambridge pp: 88-89.

32. Oliver P (2003) Dwellings: The Vernacular House World Wide. Phaidon Press, London.

33. Rapoport A (1969) House, Form and Culture. Prentice-Hall, New Jersey.

34. Rapoport A (1982) Housing and Identity: Cross-Cultural Perspectives. Holmes \& Meier Publishers, New York.

35. Rapoport A (1982) The Meaning of the Built Environment: A Nonverbal Communication Approach. Sage Publications, Beverly Hills, California.
36. Rapoport A (1984) Vernacular Architecture and the Cultural Determinants of Form. In King AD (Ed.) Buildings and Society: Essays on the Socia Development of the Built Environment. Routledge and Kegan Paul, London, Boston and Henley.

37. Rapoport A (1993) Systems of Activities and Systems of Settings. In Kent S (Eds), Domestic Architecture and the use of Space: an Interdisciplinary Crosscultural Study. Cambridge Univeristy Press, Cambridge 9-20.

38. Rapoport A (2000) Culture and built form: a reconsideration. In Moore KD (Eds), Culture - Meaning- Architecture: Critical Reflections on the Work of Amos Rapoport. Ashgate Publishing Company, Brookfield.

39. Smith, Ronald, Bugni, Valerie (2006) Symbolic Interaction Theory and Architecture. Faculty Publications

40. Kent S (1997) A Cross-cultural Study of Segmentation, Architecture, and the Use of Space. In Kent S (Ed.), Domestic Architecture and the use of Space: an Interdisciplinary Cross-cultural Study. Cambridge University Press, New York Cambridge 127-152.

41. Creswell J (1994) Research Design, Qualitative and Quantitative Approaches: Thousand Oaks. Sage Publications, California.

42. Creswell J (2003) Research Design, Qualitative and Quantitative Approaches: Thousand Oaks. Sage Publications, California.

43. Denzin NK, Lincoln YS (2005) Handbook of Qualitative Research. Sage Publications, London.

44. Dunn K (2005) Interviewing. In Hay I (Eds), Qualitative Research Methods in Human Geography. Oxford University Press, Oxford 79-105.

45. Marshall C, Rossman GB (2006) Designing qualitative research. Sage Publications, London.

46. Mason J (2001) Qualitative researching. Sage Publications, London.

47. Zeisel J (1984) Inquiry by design: Tools for Environment-Behaviour Research. Cambridge University Press, Cambridge.
Citation: Furlan R (2015) Livability and Social Capital in West Bay, The New Business Precinct of Doha. Arts Social Sci J 6: 116. doi:10.4172/2151 6200.1000116

\section{OMICS International: Publication Benefits \& Features}

\section{Unique features:}

- Increased global visibility of articles through worldwide distribution and indexing

Showcasing recent research output in a timely and updated manner

Special issues on the current trends of scientific research

Special features:

700 Open Access Journals

50,000 editorial team

Rapid review process

Quality and quick editorial, review and publication processing

Indexing at PubMed (partial), Scopus, EBSCO, Index Copernicus and Google Scholar etc

Sharing Option: Social Networking Enabled

- Authors, Reviewers and Editors rewarded with online Scientific Credits

Better discount for your subsequent articles

Submit your manuscript at: http://www.omicsonline.org/submission 